\title{
Research on the Evaluation of Emergency Logistics under Emergency Management System
}

\author{
Naiping Zhang ${ }^{1, a^{*}}$ and Xinjie Whang ${ }^{2, b}$ \\ ${ }^{1}$ Wuhan University of technology, hongshan district, wuhan city, hubei province, China \\ ${ }^{2}$ Wuhan University of technology, hongshan district, wuhan city, hubei province, China \\ a541365020@qq.com,bwxj930417@163.com
}

Keywords: Emergency management system; Emergency logistics; Dynamic research; The Analytic Network Process

\begin{abstract}
In view of the current domestic emergency logistics research direction is relatively simple and practical this paper tries to make the emergency logistics be included in the dynamic research of the emergency management system. Analyzes the key influencing factors of the emergency logistics by Combination the dynamic learning process early warning - decision - reflecting of emergency management and using the Analytic Network Process (ANP) method, and puts forward some effective suggestions on the development of emergency logistics in China.
\end{abstract}

\section{The Connotation of Emergency Logistics}

Definition of emergency logistics is divided into two kinds: one is from the perspective of emergency management, is a series of emergency goods flow process to meet the demand of emergency decision-making in; the other one is from the perspective of logistics, as a special form of modern logistics in a state of emergency.

The two explanations look similar, but the first explain strengthen the characteristics of the emergency logistics that belong to the aspect of emergency management: Sudden and unpredictability, uncertainty, demand diversity, time urgency, weak economy and social public welfare, multiple subjectivity. The second connotation define the emergency logistics as a special modern logistics form to add the seventh factor: time to the six main factors of modern logistics: fluid, carrier, flow, flow rate, flow process, flow velocity.

However, emergency management is a dynamic cycle optimization process, both the two explanations ignore this. Broader interpretation of emergency logistics should be extended to dynamic emergency resources guarantee system ,a Series of prevention store-warning response - rapid reflection-reflection optimization cycle with the dynamic process of emergency management: prevention-warning-emergency management-reflection on learning to further eliminate the adverse effects of weak preparative and improve the response speed and the ability to meet multiple demands.

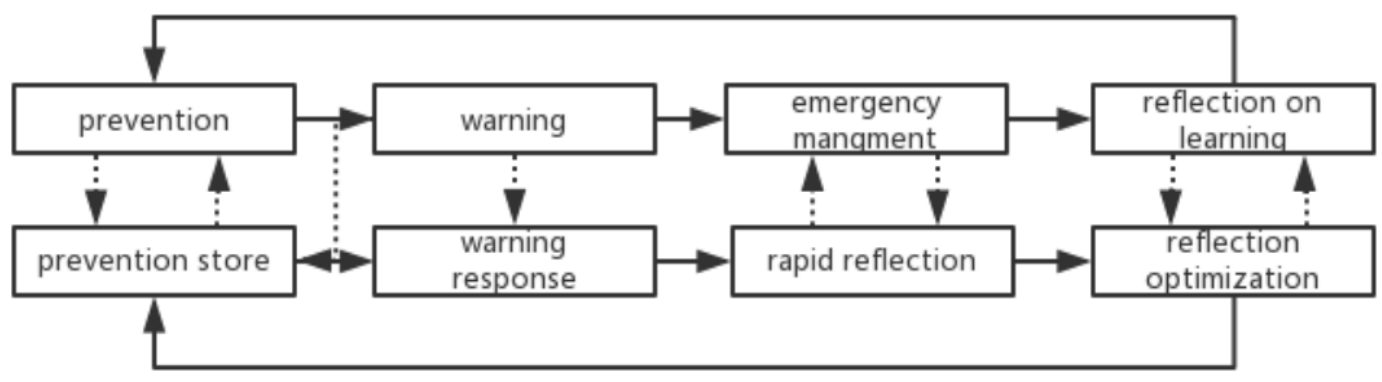

Figure 1. The relationship between emergency system and emergency logistics 


\section{The Characteristics of Emergency Logistics}

The essence of emergency logistics is still a logistics, so what it needs is to complete the financing of materials, improvement of transportation channels, choice of transport to make the target material appear in the specified space at the specified time. For emergency logistics, it has the following differences with conventional logistics:

(1)The types of transportation materials are more complicated, the sources are not uniform and the transportation is more difficult.

(2)Transportation materials are stored in fixed places as well as from mobile sites.

(3)The destination of the material is not clear before the emergency.

(4)Transportation channels may be damaged resulting in increased transport difficulty.

(5)The single transport vehicle will not be able to meet the needs of transportation, and it will be completed by means of transportation such as trains, automobiles, ships and helicopters.

(6)The demand for emergency logistics is uncertain and diverse. Emergency logistics to transport of goods is not a single fixed number like a general logistics including variety and quantity of demand such as the maintenance of life essentials, rescue items and medical products. The type and quantity of demand has also changed with the feedback of disaster relief information.

(7)Economy has less constraint on emergency logistics, and emergency logistics has public welfare and less consideration of cost.

(8)The most important is the timeliness of emergency logistics is very strong 。 Emergency management's ultimate goal is to maximizing protection the state and people's life and property security, corresponding the goal of the emergency logistics is to deliver urgently needed supplies to the affected areas within the shortest possible time.

\section{Analysis of the impact factors of Emergency logistics}

On the basis of emergency logistics in a certain area, Combining the characteristics of the above analysis and the dynamic cycle of emergency logistics, The influence 15 factors of emergency logistics capacity are divided into three factors:

(1)Reserve capacity of emergency materials. The concept of precautionary prevention is strengthened in order to realize the rapid response to emergencies.

(1)The completeness and flexibility of contingency plan. Contingency plan is the basis of emergency management. The effective contingency plan can include specific provisions for some basic problems and the ability to respond to irregular problems.

(2)Legal and institutional safeguards. The law and system guarantee the actual implementation capacity of the emergency resources protection plan with its enforcement ability. It is essential to the smooth implementation of emergency logistics. There are 《the national emergency plan for national emergencies》 、 《the emergency response law》 and others in china. In 《the planning of logistics adjustment and revitalization》 emergency logistics is also emphasized as a special logistics form of logistics.

(3)rationality of the layout of the material reserve center. The layout of the reserve center includes the size and geographical location of the center, which affect each other. The large reserve center has a large range of radiation and high operating costs.

(4) the diversity of material reserves. Emergency logistics emphasizes fast reflection, and the emergency material reserve must be carried out on the basis of analysis needs to realize effective material reserve.

(5)quantity of materials. In the face of the emergency management of multiple supplies demand, the demand of different kinds of material are different, Accurate analysis of the demand quantity of different materials is another factor to form effective reserves 
(6) The sharing of material reserve information. A single reserve center cannot meet reserve requirements. The reserve information of different reserve centers is Shared, so as to form a dynamic adjustment of the central material reserve, and realize the optimization of national overall reserve

(7) the cost of material reserves. Lower reserve costs also mean that some reserves can be added under the same conditions.

(2)Quick response and response ability. The key ability to realize the target of emergency logistics. The warning of emergency is the starting signal of respond and based on reserves of reserves .

(1)Information acquisition and feedback analysis capability. Quickly acquired, analyzed and feedback of information, The reaction time of each link can be shortened and realized the flexible adjustment and optimization of the emergency material transportation scheme

(2)Coordination ability of decision-makers. The incident itself is a kind of unconventional event, and the process is flexible. In the dynamic process of emergency logistics, decision-makers constantly faces information updates, optimizes the source of materials and channels of transportation, and adjusts the destination. The overall coordination capacity of decision-makers will have a huge impact on the final outcome.

(3) Quick financing of materials. When material reserves cannot meet the demand, how to obtain the required materials in a short time through compulsory requisition, emergency purchase or production, collection and other means becomes an important capability for emergency logistics.

(4)The ability to use high and new equipment and technology. Emerging technologies and equipment such as geographic information system (GIS) and integrated database will enable accurate and timely collection and analysis of information, and assist in making scientific decisions.

(5)The integrity of the material transport. In the process of material transportation, the selection of material sources, transportation channels and transportation tools will affect the loss of materials in the way, thus affecting the usability of the materials.

(6) Material transportation cost.

(3)Reflection and optimization. Reflection optimization is an important ability to connect the dynamic cycle of emergency logistics. In fact, it is the most important capacity to enhance the emergency logistics.

(1) learning ability of related management knowledge skills. Only the relevant personnel of emergency logistics can master and update relevant management knowledge and skills continuously, and the emergency logistics system has the ability to reflect and optimize.

(2) Reflect on the awareness of optimization. Reflective optimization is often overlooked, The main reason is the lack of circular optimization consciousness. In order to realize the dynamic optimization of emergency logistics, the optimal reflection can be used as a fixed link in the whole cycle.

There is a close connection between the factors influencing the three levels of emergency logistics, and the three are interrelated and mutually restrained, and jointly restrict the ability of emergency logistics.

The prevention reserve ability of urgent logistics is the basic support of emergency logistics capability. Strengthening the concept of precautionary prevention, obtaining the general demand of emergency logistics through scientific statistical analysis, and constructing the reasonable operation mechanism and personnel structure, build the foundation for the timely and accurate response of emergency logistics.

The quick response and response ability of emergency logistics is the key ability of emergency logistics. ensure that emergency logistics coordinate all aspects of the response process, effectively realize the ultimate goal of emergency logistics.

The reflection and optimization ability of emergency logistics is a key ability to make a big impact on the future development of emergency logistics. This capability creates a spiral rise cycle for the development of emergency logistics and continuously improves the overall capability of emergency logistics, thus further improving the emergency management system of emergencies. 


\section{The Characteristics of Emergency Logistics}

Construction of evaluation index system for emergency logistics capability

Based on the analysis of the factors influencing the emergency logistics capacity, the ability of emergency logistics is considered from the third level of 15 factors. The evaluation index system of emergency logistics capability is shown in the following table:

Table 1 evaluation index system

\begin{tabular}{|c|c|c|}
\hline The target layer & The rule layer & The index layer \\
\hline \multirow{15}{*}{$\begin{array}{l}\text { Emergency logistics } \\
\text { capability A }\end{array}$} & \multirow{7}{*}{$\begin{array}{r}\text { Reserve } \\
\text { capacity of } \\
\text { emergency } \\
\text { materials B }\end{array}$} & The completeness and flexibility of contingency plan B1 \\
\hline & & Legal and institutional safeguards B2 \\
\hline & & Rationality of the layout of the material reserve center B3 \\
\hline & & The diversity of material reserves B4 \\
\hline & & Quantity of materials B5 \\
\hline & & The sharing of material reserve information B6 \\
\hline & & The cost of material reserves B7 \\
\hline & \multirow{6}{*}{$\begin{array}{c}\text { Quick response } \\
\text { and response } \\
\text { ability C }\end{array}$} & $\begin{array}{l}\text { Information acquisition and feedback analysis capability } \\
\qquad \mathrm{C} 1\end{array}$ \\
\hline & & Coordination ability of decision-makers $\mathrm{C} 2$ \\
\hline & & Quick financing of materials C3 \\
\hline & & $\begin{array}{l}\text { The ability to use high and new equipment and technology } \\
\text { C4 }\end{array}$ \\
\hline & & The integrity of the material transport $\mathrm{C} 5$ \\
\hline & & Material transportation cost C6 \\
\hline & \multirow{2}{*}{$\begin{array}{l}\text { Reflection and } \\
\text { optimization D }\end{array}$} & $\begin{array}{l}\text { Learning ability of related management knowledge skills } \\
\text { D1 }\end{array}$ \\
\hline & & Reflect on the awareness of optimization D2 \\
\hline
\end{tabular}

From the analysis of the third part, it can be seen that there is no independent influence on the ability of emergency logistics, and their mutual influence is restricted. For example, the ability to prevent reserve is better, so the speed of response and the accuracy of the response can be further improved. The ability to respond quickly and respond is relatively strong, and the demand for the prevention of reserve capacity is relatively low in the case of the same material demand. The different levels of factors interact with each other, too. For example, the learning ability of relevant management knowledge skills is high, so the completeness and flexibility of emergency resources protection plan will be further enhanced after the review and optimization.

In the face of the mutual constraints between these factors, the paper focuses on the analysis of the whole evaluation system by focusing on the network analysis (ANP) which focuses on the interrelationship among factors.

Evaluation method using nine points to two between two elements relative to the importance of the impact on the emergency logistics capability, 1 said the same to the importance of the two elements, from 1 to 9 than after a previous elements gradually increased, to the importance of the 9 indicates the importance of a element after the previous element relatively extreme high.

By looking at the literature and the expert's method, the criterion layer two and two important degree of judgment matrix: 
Table 2 comparison matrix of criterion layer

Complete the comparison matrix of index layer:

\begin{tabular}{|l|l|l|l|}
\hline & $\mathrm{B}$ & $\mathrm{C}$ & $\mathrm{D}$ \\
\hline $\mathrm{B}$ & 1 & 5 & 3 \\
\hline $\mathrm{C}$ & $1 / 5$ & 1 & $1 / 4$ \\
\hline $\mathrm{D}$ & $1 / 3$ & 4 & 1 \\
\hline
\end{tabular}

Table 3 comparison matrix of index layer network

( 1 indicates that the indicators on the left and the indexes above have an impact, 0 indicates no impact)

\begin{tabular}{|c|c|c|c|c|c|c|c|c|c|c|c|c|c|c|c|}
\hline & $\mathrm{B}_{1}$ & $\mathrm{~B}_{2}$ & $\mathrm{~B}_{3}$ & $\mathrm{~B}_{4}$ & $\mathrm{~B}_{5}$ & $\mathrm{~B}_{6}$ & $\mathrm{~B}_{7}$ & $\mathrm{C}_{1}$ & $\mathrm{C}_{2}$ & $\mathrm{C}_{3}$ & $\mathrm{C}_{4}$ & $\mathrm{C}_{5}$ & $\mathrm{C}_{6}$ & $\mathrm{D}_{1}$ & $\mathrm{D}_{2}$ \\
\hline $\mathrm{B}_{1}$ & 0 & 1 & 1 & 1 & 1 & 1 & 1 & 0 & 0 & 1 & 1 & 0 & 1 & 1 & 1 \\
\hline $\mathrm{B}_{2}$ & 1 & 0 & 0 & 0 & 1 & 1 & 0 & 0 & 0 & 0 & 1 & 0 & 0 & 1 & 0 \\
\hline $\mathrm{B}_{3}$ & 1 & 0 & 0 & 1 & 1 & 1 & 1 & 0 & 0 & 1 & 0 & 1 & 1 & 1 & 0 \\
\hline $\mathrm{B}_{4}$ & 1 & 0 & 1 & 0 & 1 & 1 & 1 & 0 & 0 & 1 & 0 & 1 & 1 & 1 & 0 \\
\hline $\mathrm{B}_{5}$ & 1 & 1 & 1 & 1 & 0 & 0 & 1 & 0 & 1 & 1 & 0 & 0 & 1 & 0 & 0 \\
\hline $\mathrm{B}_{6}$ & 1 & 1 & 1 & 1 & 0 & 0 & 1 & 0 & 0 & 1 & 0 & 0 & 1 & 1 & 0 \\
\hline $\mathrm{B}_{7}$ & 1 & 0 & 1 & 1 & 1 & 1 & 0 & 0 & 0 & 1 & 1 & 0 & 1 & 0 & 0 \\
\hline $\mathrm{C}_{1}$ & 0 & 0 & 0 & 0 & 0 & 0 & 0 & 0 & 1 & 1 & 1 & 1 & 1 & 1 & 0 \\
\hline $\mathrm{C}_{2}$ & 0 & 0 & 0 & 0 & 1 & 0 & 0 & 1 & 0 & 1 & 1 & 1 & 1 & 0 & 1 \\
\hline $\mathrm{C}_{3}$ & 1 & 0 & 1 & 1 & 1 & 1 & 1 & 1 & 1 & 0 & 1 & 0 & 1 & 0 & 0 \\
\hline $\mathrm{C}_{4}$ & 1 & 1 & 0 & 0 & 0 & 0 & 1 & 1 & 1 & 1 & 0 & 1 & 1 & 1 & 1 \\
\hline $\mathrm{C}_{5}$ & 0 & 0 & 1 & 1 & 0 & 0 & 0 & 1 & 1 & 0 & 1 & 0 & 1 & 1 & 0 \\
\hline $\mathrm{C}_{6}$ & 1 & 0 & 1 & 1 & 1 & 1 & 1 & 1 & 1 & 1 & 1 & 1 & 0 & 1 & 1 \\
\hline $\mathrm{D}_{1}$ & 1 & 1 & 1 & 1 & 0 & 1 & 0 & 1 & 0 & 0 & 1 & 1 & 1 & 0 & 1 \\
\hline $\mathrm{D}_{2}$ & 1 & 0 & 0 & 0 & 0 & 0 & 0 & 0 & 1 & 0 & 1 & 0 & 1 & 1 & 0 \\
\hline
\end{tabular}

In this way, a 15-column 15-column matrix is formed, which is difficult to calculate. The computer software Super Decision is used to calculate the matrix, and the ANP value of the index is as follows: 
Table 4 evaluation index ANP value of emergency logistics capability

\begin{tabular}{|c|c|c|c|c|}
\hline The target layer & The rule layer & The index layer & $\begin{array}{l}\text { ANP value } \\
\text { (weight) }\end{array}$ & rank \\
\hline \multirow{2}{*}{$\begin{array}{c}\text { Emergency logistics } \\
\text { capability A }\end{array}$} & \multirow{7}{*}{$\begin{array}{l}\text { Reserve } \\
\text { capacity of } \\
\text { emergency } \\
\text { materials B }\end{array}$} & $\begin{array}{l}\text { The completeness and } \\
\text { flexibility of contingency } \\
\text { plan } B_{1}\end{array}$ & 10.87 & 2 \\
\hline & & $\begin{array}{c}\text { Legal and institutional } \\
\text { safeguards } \mathrm{B}_{2}\end{array}$ & 8.65 & 5 \\
\hline & & $\begin{array}{l}\text { Rationality of the layout of } \\
\text { the material reserve center } \\
\qquad \mathrm{B}_{3}\end{array}$ & 8.49 & 6 \\
\hline & & $\begin{array}{c}\text { The diversity of material } \\
\text { reserves } \mathrm{B}_{4}\end{array}$ & 7.96 & 7 \\
\hline & & Quantity of materials B5 & 7.21 & 9 \\
\hline & & $\begin{array}{l}\text { The sharing of material } \\
\text { reserve information } B_{6}\end{array}$ & 7.58 & 8 \\
\hline & & $\begin{array}{c}\text { The cost of material } \\
\text { reserves } B_{7}\end{array}$ & 1.97 & 14 \\
\hline & \multirow{6}{*}{$\begin{array}{l}\text { Quick } \\
\text { response and } \\
\text { response } \\
\text { ability C }\end{array}$} & $\begin{array}{c}\text { Information acquisition and } \\
\text { feedback analysis capability } \\
\mathrm{C}_{1}\end{array}$ & 9.57 & 3 \\
\hline & & \begin{tabular}{|c|} 
Coordination ability of \\
decision-makers $\mathrm{C}_{2}$
\end{tabular} & 12.32 & 1 \\
\hline & & $\begin{array}{l}\text { Quick financing of materials } \\
\mathrm{C}_{3}\end{array}$ & 9.14 & 4 \\
\hline & & $\begin{array}{c}\text { The ability to use high and } \\
\text { new equipment and } \\
\text { technology } C_{4}\end{array}$ & 4.43 & 10 \\
\hline & & $\begin{array}{c}\text { The integrity of the material } \\
\text { transport } C_{5}\end{array}$ & 3.46 & 11 \\
\hline & & \begin{tabular}{|c|} 
Material transportation cost \\
$\mathrm{C}_{6}$ \\
\end{tabular} & 1.74 & 15 \\
\hline & \multirow{2}{*}{$\begin{array}{l}\text { Reflection } \\
\text { and } \\
\text { optimization } \\
\text { D }\end{array}$} & $\begin{array}{c}\begin{array}{c}\text { Learning ability of related } \\
\text { management knowledge } \\
\text { skills } \mathrm{D}_{1}\end{array} \\
\end{array}$ & 2.30 & 12 \\
\hline & & $\begin{array}{c}\text { Reflect on the awareness of } \\
\text { optimization } \mathrm{D}_{2}\end{array}$ & 2.05 & 13 \\
\hline
\end{tabular}

After calculation, the importance of the various factors that affect the emergency logistics capability are display. Combined with various influencing factors of importance and the present situation of emergency logistics of emergency logistics development in our country, put forward the following Suggestions.

\section{The Characteristics of Emergency Logistics}

Combined with the development status of China's emergency logistics and the result of ANP analysis, the factors that affect the emergency logistics capacity are the most important, and some Suggestions for the future development of logistics are given.

(1)The coordination ability of decision makers has the highest weight among many influencing 
factors. The emergency logistics compared general logistics, the subjective initiative of the person has been better reflected, the overall coordination played a key role in the success or failure. The role of the commanders in the relevant management and professional knowledge has been highlighted, and the professional team building in this area has some shortcomings. In the future, we should strengthen the training of higher talents in our country, absorb international advanced theory and technology, combine the present situation of our country, and build an emergency logistics system with Chinese characteristics.

(2)The importance of emergency resources plans don't need much elaboration, emergency logistics operational mechanism, personnel organization and a series of emergency logistics process in the plan have been varying degrees of embodiment. Emergency plan should be based on the construction of a contingency plans a complete dynamic cycle, on the basis of collection of the past experience and advanced management knowledge and skills, realize the perfection of emergency plan and the flexibility to build. However, the existing contingency plan in China is basically the same pattern, the combination degree of the actual situation is not high, Poor practicality .In the future plans should set up corresponding laws and regulations system to do guidance, set up different levels of mutual cooperation plan system, implementation plan in the face of the sudden emergencies strong enforceability and reliability.

(3)Information acquisition and feedback analysis ability and the sharing of material reserve information are important, which shows the urgency and importance of informatization of emergency 。 logistics. Accurate and timely unified information is the basis of scientific decision-making. The establishment of a unified emergency information sharing platform will not only enhance the effectiveness of emergency logistics, but will have a huge positive impact on the whole emergency management system. Combined with the use of various high precision positioning identification system, a fast and efficient and accurate information transmission system across different levels is formed. On the other hand, new media can be used as the medium of information transmission, reducing the time cost of information transmission and increasing the amount of information transmitted. At the same time, it can also more effectively placate popular emotions, curb the spread of rumors, improve the credibility of the party and government in the public's mind, and reduce the possibility of the occurrence of derivative disasters.

\section{References}

[1] Zhongwen $\mathrm{Ou}$, HuiyunWang , Liangli Jiang et al, Emergency logistics ,J. Journal of chongqing university, 2004,27(3):164-167

[2] Yong Zhao, Shaojuan Feng, Jia Liu, Research on emergency logistics risk analysis, J. Logistics technology, 2006, 29 (133) : 9-13

[3] Wang Feng, Jiang Yuhong, Jin Wang, Emergency logistics M. Beijing: China materials press, 2007.

[4] Ruhe Xie, Zhu Qiu, On the construction of emergency logistics system and its operation management ,J. Logistics technology, 2005 (10) : 78-80

[5] Xujie Ren, Chunming Ye, Selection of emergency logistics solutions based on fuzzy analytic hierarchy process ,J. Logistics technology, 2008 (10) : 01-03

[6] Hui Chen. The main problems and optimization recommendations of China's emergency logistics system ,J. China circulation economy, 2014 (8) : 20-24

[7] Xiaoguang Guo, Research on the planning and operation of emergency logistics network for natural disasters ,D. Beijing jiaotong university, 2013 